\title{
MANAJEMEN RISIKO WAKAF DI DOMPET DHUAFA
}

\section{RISK MANAGEMENT OF WAKAF IN DOMPET DHUAFA}

\author{
Desy Ery Kuncorowati*1, Noer Azzam Achsani* ${ }^{* *}$, dan Didin Hafidhuddin ${ }^{* * *}$ \\ *) PT. United Tractors Tbk \\ Jl. Raya Bekasi Km. 22 Cakung, Jakarta Timur 13910 \\ ${ }^{* *}$ Sekolah Bisnis, Institut Pertanian Bogor \\ Jl. Raya Pajajaran, Bogor 16151 \\ ${ }^{* * *)}$ Universitas Ibn Khaldun Bogor \\ J1. Baru, Tanah Sereal, Kota Bogor 16162
}

\begin{abstract}
The purpose of this research were to analyze problem mapping in managing land wakaf activity from the process of fundrising, managing , and distribution of waqf benefit by enterprise risk management (ERM) COSO approach. Identifying and measuring every potential risk in wakaf activity to analyzing and preparing mitigation strategy. The research was conducted at Dompet Dhuafa Head Office, Philantrophy Building, South Jakarta. The technique of measuring and mapping risks according to Godfrey (1996). Data collection consisted of four stages: interview, questioner, focus group discussion, and literature review. The result showed there are 47 risks in land wakaf management. There were 20 high risk, 15 medium risks, and 12 low risk.
\end{abstract}

Keywords: risk management, wakaf, erm, land waqf, cash waqf, Dompet Dhuafa

\begin{abstract}
Abstrak: Penelitian ini menganalisis peta masalah pada kegiatan manajemen wakaf tunai dan tanah/bangunan mulai dari proses manajemen penghimpunan, pengelolaan dan pengembangan, hingga penyaluran dengan pendekatan enterprise risk management (ERM) COSO. Mengidentifikasi dan mengukur setiap potensi risiko tersebut kemudian menganalis strategi mitigasi atas setiap risiko dan strategi manajemen risiko yang harus disiapkan untuk setiap kegiatan manajemen wakaf. Analisis penelitian ini menggunakan teknik pengukuran dan pemetaan mengacu pada Godfrey (1996). Tehnik pengumpulan data menggunakan empat tahap, yaitu wawancara, kuisioner, Focus Group Discussion (FGD), Studi Pustaka. Hasil penelitian menunjukkan bahwa risiko manajemen wakaf tanah/banguanan teridentifikasi sebanyak 47 risiko, terdiri dari 21 risiko tinggi, 15 risiko sedang, dan 11 risiko rendah.
\end{abstract}

Kata kunci: manajemen risiko, ERM, wakaf tanah, wakaf uang, dompet dhuafa

\footnotetext{
${ }^{1}$ Alamat Korespondensi:

Email: desyeryk@gmail.com
} 


\section{PENDAHULUAN}

Selain zakat dan sedekah, dalam keuangan syariah dikenal pula konsep wakaf. Wakaf ini memiliki potensi sangat besar di sektor keuangan syariah dan mempunyai potensi mempercepat pembangunan infrastruktur, fasilitas sosial, dan juga sarana keagamaan. Dalam wallstreet journal seperti yang dikutip oleh Nizamoglu (2011) bahkan menyarankan penyelesaian krisis dunia dengan menjalankan konsep wakaf, dimana sejumlah milyuner dunia dapat berpartisipasi untuk membangun infrastuktur negara untuk kepentingan rakyat kelas menengah bawah. Data dari Kementerian Agama tahun 2012 menunjukkan, aset wakaf nasional mencapai 3,49 miliar meter persegi tanah, pada 420.003 titik di seluruh nusantara. Wakaf yang ada di Indonesia menurut kalkulasi dari lembaga perwakafan jika dikumpulkan maka luasnya sebanding dengan negara Singapura.

Tidak hanya itu, dengan disahkannya Undang-Undang Wakaf Nomor 41 Tahun 2004 yang mengakui keabsahan wakaf uang, kita berpotensi mempunyai aset wakaf uang yang juga sangat fantastis. Sesuai data BPS tahun 2015 jumlah muslim Indonesia sekitar 207 juta jiwa (88\% dari total populasi penduduk). Menurut world bank dalam Widiatmanti (2015), jumlah data penduduk kelas menengah di Indonesia pada tahun 2010 berjumlah 134 juta jiwa atau 56,5\% dari populasi. Menurut studi Bank Dunia, kalangan kelas menengah ini terbagi dalam empat kelas seperti terlihat pada Gambar 1. Pertama kelas menengah dengan pendapatan US\$2-US\$4 atau Rp2,6-5,2 juta per bulan (38,5\%). Kedua, kelas menengah dengan pendapatan US\$4-6 atau Rp5,2 -7,8 juta perkapita perbulan (11,7\%).Ketiga kelas menengah dengan pendapatan US\$6-US\$10 atau Rp7,8-13 juta perbulan (5\%) serta golongan menengah berpendapatan
US\$10-US\$20 atau Rp13-26 juta perbulan (1,3\%). Dengan asumsi populasi muslim Indonesia adalah $88 \%$ maka dapat dibuat perhitungan potensi perolehan dana wakaf tunai seperti yang tergambar pada Tabel 1.

Jumlah potensi wakaftunai tersebut hampirsama dengan pendapatan pajak negara yang berasal dari PPH 21 tahun 2014 sebanyak 105 triliun menurut laporan realisasi penerimaan pajak dari dirjen pajak. Tapi faktanya, potensi wakaf uang dan aset tanah wakaf masih sangat sedikit yang dikelola secara produktif. Sebagian besar masih berupa wakaf konsumtif seperti masjid, kuburan dan sekolah, yang masih menengadahkan tangan untuk menutupi biaya operasionalnya. Berdasarkan penelitian Pusat Bahasa dan Budaya (PBB) UIN Syarif Hidayatullah Jakarta terhadap 500 responden nazir (pengelola wakaf) di 11 Propinsi menunjukkan, harta wakaf lebih banyak bersifat diam (77\%) daripada yang menghasilkan atau produktif $(23 \%)$. Temuan umum lainnya juga menunjukkan pemanfaatan terbesar harta wakaf adalah masjid (79\%) daripada peruntukkan lainnya, dan lebih banyak berada di wilayah pedesaan (59\%) daripada perkotaan (41\%). Sedangkan para nazir pun tidak terfokus dalam mengelola, mereka mayoritas bekerja sambilan dan tidak diberi upah (84\%), dan yang bekerja secara penuh dan terfokus ternyata amatlah minim (16\%). Selain itu, wakaf di Indonesia lebih banyak dikelola oleh perseorangan $(66 \%)$ alias tradisional, daripada organisasi professional (16\%) dan berbadan hukum (18\%) (Ubaid, 2009). Menurut Arifin (2015) dilema produktifitas tanah wakaf di Indonesia diantaranya karena sebagian besar adalah berbentuk masjid dan nazir tidak fokus mengelola aset wakaf karena dijadikan pekerjaan sambilan dan tidak diberi upah.

Tabel 1. Potensi wakaf uang di Indonesia (dalam Rp)

\begin{tabular}{ccccc}
\hline $\begin{array}{c}\text { Tingkat penghasilan } \\
\text { per bulan }\end{array}$ & Jumlah muslim & Wakaf perbulan & $\begin{array}{c}\text { Potensi wakaf tunai } \\
\text { per bulan }\end{array}$ & $\begin{array}{c}\text { Potensi wakaf tunai } \\
\text { per tahun }\end{array}$ \\
\hline $2,6-5,2$ juta & 80 Juta & 50.000 & $4 \mathrm{~T}$ & $48 \mathrm{~T}$ \\
$5,2-7,8$ juta & 24 juta & 100.000 & $2,5 \mathrm{~T}$ & $30 \mathrm{~T}$ \\
$7,8-13$ juta & 10 Juta & 200.000 & $2 \mathrm{~T}$ & $24 \mathrm{~T}$ \\
$13-26$ juta & 2.7 juta & 300.000 & $800 \mathrm{M}$ & $9,6 \mathrm{~T}$ \\
\hline & & Total & $9,3 \mathrm{~T}$ & $111,6 \mathrm{~T}$ \\
\hline
\end{tabular}


Ketidakmaksimalan pengelolaan potensi wakaf yang ada disebabkan oleh banyak hal yang menjadi bagian dari risiko manajemen wakaf yang belum maksimal. Disinilah Dompet dhuafa sebagai salah satu nazir nasional yang profesional perlu mengimplementasikan manajemen risiko pada proses organisasi agar dapat meningkatkan kemungkinan tercapainya sasaran organisasi dan meningkatkan kemampuan untuk mengimplementasi mendekati potensinya. Manajemen risiko juga akan mendorong manajemen lebih proaktif dan mampu mengidentifikasi peluang dan ancaman pada setiap proses dalam organisasi dengan cara menghindari atau mengurangi dampak risiko agar dapat meningkatkan kebermanfaatan di masyarakat dan negara. Manajemen risiko memiliki peran penting dalam mewujudkan tata kelola perusahaan melalui manajemen risiko yang efektif, sehingga perusahaan dapat meminimalkan risiko dan dampak (Pradana dan Rikumahu, 2014). Organisasi yang melakukan proses manajemen risiko juga dapat menciptakan nilai tambah, karena potensi return yang diperoleh sudah diperhitungkan lebih besar daripada potensi risiko kerugiannya (Gondo dan Wibowo, 2015).

Untuk menganalisa keterkaitan atas ketidaktercapaian potensi wakaf melalui pelaksanaan manajemen risiko maka penelitian ini akan dilakukan dengan metode Enterprises Risk Management (ERM) COSO, dimana tujuan manajemen risiko tidak hanya dilihat dari sisi strategik, tapi juga dari sisi operasional, pelaporan dan kepatuhan. Risiko pada bagian operasional mencakup risiko dalam proses penghimpunan dana wakaf, pengelolaan harta dan dana wakaf, serta manajemen penyaluran dana wakaf. Risiko pada bidang reporting mencakup risiko pada pelaporan data internal dan data eksternal ke stakeholders. Risiko kepatuhan mencakup risiko pada kepatuhan terhadap peraturan dan undangudang yang berlaku, seperti Undang-Undang Nomor 41 Tahun 2004 tentang Wakaf dan berbagai peraturan lainnya. ERM penting diterapkan mulai dari usaha skala kecil, micro dan menengah agar mampu menghadapi berbagai risiko dalam pertumbuhan ekonomi dan pengembangan bisnis (Masama et al. 2012).

Penelitian terdahulu mengenai manajemen risiko menggunakan beberapa metode seperti Rozalinda (2012) mengenai manajemen risiko investasi wakaf uang tidak memetakan risiko menggunakan metode Godfrey tapi tetap mengacu pada prinsip ERM COSO. Penelitian Wasisto (2013) dan Wiryani (2013) tidak menggunakan standart ISO 31000 untuk penelitiannya. Sedangkan penelitian Triyani (2015) hanya manajemen risiko zakat saja tidak pada bidang wakaf. Hasil penelitian manajen risiko dari penelitian sebelumnya seperti penelitian Arnold et al. (2003) yang menguji pengaruh ERM pada proses peningkatan kemampuan supply chain untuk mengurangi risiko yang berjudul Enterprise Risk Management as a Strategic Governance Mechanism in B2B-Enabled Transnational Supply Chains menunjukkan bahwa implementasi ERM membuat risiko B2B lebih rendah, risiko bisnis global lebih rendah, kinerja perusahaan dinilai baik dimata stake holder, dan kondusif jika kinerja rantai pasok perusahaan kuat. Tsabita (2014) dalam penelitian analisis risiko pembiayaan syariah pada sektor pertanian juga menggunakan ERM COSO dengan temuan risiko utama yaitu nasabah gagal bayar karena sebab moral hazard.

Perbedaan penelitian ini dengan penelitian pendahulunya terutama pada objek penelitian yaitu manajemen risiko pada bidang keuangan sosial dan wakaf, karena saat ini masih sangat sedikit penelitian mengenai manajemen risiko wakaf. Penelitian ini menjadi penting karena belum ada penelitian sebelumnya mengenai manajemen wakaf pada lembaga nazir, baik untuk manajemen risiko wakaf tanah/ bangunan maupun wakaf uang.

Tujuan penelitian ini adalah untuk mengidentifikasi potensi-potensi risiko yang mungkin muncul pada proses manajemen wakaf di dompet dhuafa. Kemudian mengukur dan memetakan hasil identifikasi risiko agar diketahui tingkat risikonya. Hasil pemetaan tingkat risiko akan menjadi acuan mitigasi risiko dalam manajemen wakaf di dompet dhuafa. Penelitian ini dibatasi hanya terkait manajemen wakaf di dompet dhuafa dan hanya untuk jenis wakaf tunai dan wakaf tanah atau bangunan saja, meliputi proses manajemen himpunan, manajemen pengelolaan, dan manajemen penyaluran wakaf.

\section{METODE PENELITIAN}

Penelitian dilaksanakan di kantor pusat Dompet Dhuafa, Jakarta Selatan pada November sampai dengan Desember 2016. Data yang digunakan dalam penelitian ini adalah data primer dan sekunder. Data primer didapatkan dari hasil wawancara dengan responden dari pakar dan ahli dalam bidang wakaf serta dari team wakaf dompet dhuafa yang berkompeten untuk 
memberikan penilaian risiko dan merekomendasikan strategi mitigasi risiko di dompet dhuafa. Sedangkan data sekunder didapatkan dari data laporan keuangan dan data-data internal dompet dhuafa, serta dari literatur yang relevan lain seperti jurnal ilmiah, penelitian terdahulu, buku, dan internet.

Responden dipilih berdasarkan metode purposive sampling, yaitu responden dipilih dengan sengaja karena dianggap memiliki pengetahuan, keahlian, dan kompetensi dalam bidang yang dikaji. Wawancara dilakukan untuk menentukan strategi mitigasi risiko. Selain itu dilakukan pula metode forum discussion group (FGD) bersama beberapa manajer wakaf dompet dhuafa untuk mengidentifikasi setiap potensi risiko pada proses manajemen wakaf di dompet dhuafa.

Data yang dikumpulkan dalam penelitian ini menggunakan beberapa metode, yaitu wawancara dengan beberapa pakar dan manajer dompet dhuafa dengan teknik deep interview untuk mendapatkan rekomendasi strategi mitigasi risiko yang sebaiknya dilakukan dompet dhuafa. Selanjutnya, melalui FGD dilakukan dengan kepala-kepala bidang yang dipandang memahami dengan baik bidang-bidang yang dikelolanya untuk mengidentifikasi setiap potensi risiko pada proses manajemen wakaf dompet dhuafa. Kuisioner diberikan kepada responden dari team wakaf dompet dhuafa untuk mengukur hasil identifikasi risiko dari sisi besaran peluang dan besaran dampak setiap risiko terhadap operasional wakaf di dompet dhuafa. Di samping itu, melakukan studi pustaka untuk mendapatkan data sekunder sebagai pedoman penelitian.

Identifikasi risiko dilakukan berurutan sesuai proses kerja yang tercantum pada Standart Operation Procedure (SOP) wakaf dompet dhuafa pada proses kerja manajemen wakaf tanah/bangunan. Hasil identifikasi risiko adalah daftar potensi risiko yang ditemukan pada setiap proses kerja berdasarkan tujuan manajemen risiko dan risk apetite organisasi.

Daftar risiko tersebut kemudian diukur mengunakan skala likert 1 sampai 5 dengan metode pengukuran risiko menurut Godfrey (1996). Pengukuran dilihat dari sisi peluang (probability) dan sisi dampak (impact) atas risiko yang berpotensi terjadi, dengan dampak dan peluang terkecil adalah angka 1 dan yang terbesar adalah angka 5. Nilai risiko didapatkan dari hasil kali tingkat peluang dan tingkat dampak. Skala probabilitas dan dampak selengkapnya pada Tabel 2.

Setelah diukur agar lebih mudah di analisa kemudian nilai risiko dipetakan sesuai dengan tingkat penerimaan risikonya. Berdasarkan kecenderungan peluang terjadinya risiko dan dampak yang diakibatkan, Godfrey (1996) membagi empat tingkat penerimaan risiko, yaitu Unacceptable (risiko yang tidak dapat diterima dan harus dihilangkan); Undesirable (risiko yang tidak diharapkan dan harus dihindari); Acceptable (risiko yang dapat diterima); Negligible (risiko yang sepenuhnya dapat diterima). Hasil pemetaan penerimaan risiko akan menjadi dasar penentuan respon risiko dan strategi mitigasi yang tepat untuk setiap risiko. Menurut Flaganan dan Norman (1993) untuk menentukan respon terhadap risiko bisa dibagi dalam empat level seperti Tabel 3. Teknik pengolahan dan analisis data mengacu pada komponen-komponen proses manajemen risiko ERM COSO yang disesuaikan dalam kerangka pemikiran penelitian yang tergambar pada Gambar 2.

\section{HASIL}

Mengacu pada tiga komponen pertama dari delapan komponen COSO Standard of Enterprise Risk Management Integrated Framework, yaitu internal environtmen, objective setting, dan event identification. Faktor internal terpenting bagi Dompet Dhuafa pertama adalah reputasi organisasi yang terpercaya oleh masyarakat. Kedua, Dompet Dhuafa juga dikenal memiliki hubungan kerjasama yang luas dengan lembaga terkait lainnya diseluruh Indonesia baik dari kalangan pemerintahan maupun swasta. Ketiga, memiliki struktur organisasi yang lengkap dan stabil serta sistem operasional yang efektif menjadi salah satu kunci sukses Dompet Dhuafa.

Tabel 2 Skala probabilitas dan dampak

\begin{tabular}{cll}
\hline Angka & Skala probabilitas & Skala dampak \\
\hline 1 & Sangat Jarang & Sangat kecil \\
2 & Jarang & Kecil \\
3 & Kadang-kadang & Sedang \\
4 & Sering & Besar \\
5 & Sangat Sering & Sangat besar \\
\hline
\end{tabular}

Sumber: Godfrey (1996) 
Tabel 3. Level risiko, tingkat penerimaan dan respon risiko

\begin{tabular}{lll}
\hline \multicolumn{1}{c}{ Level } & \multicolumn{1}{c}{ Tingkat Penerimaan } \\
\hline Ekstrim $($ Extreme $)$ & Tidak dapat diterima (Unacceptable) & Menghindari risiko (risk avoidance) \\
Tinggi $($ High $)$ & Tidak diharapkan (Undesirable) & Mentransfer risiko (risk transfer) \\
Sedang $($ Medium $)$ & Bisa diterima (Acceptable) & Mengurangi risiko (risk reduction) \\
Rendah $($ Low $)$ & Bisa diabaikan (Negligible) & Menerima risiko (risk acceptable) \\
\hline
\end{tabular}



Gambar 2. Kerangka pemikiran penelitian

Objective setting manajemen risiko Dompet Dhuafa ditetapkan sejalan dengan misi organisasi yaitu Meningkatkan pemahaman dan kesadaran masyarakat akan pentingnya potensi dan peran wakaf dalam berkontribusi bagi peningkatan kesejahteraan masyarakat; Menggalang seluas-luasnya dukungan sumber daya masyarakat dalam mewujudkan peran wakaf untuk berkontribusi aktif meningkatkan kesejahteraan masyarakat; Memastikan pengelolaan yang optimal seluruh harta wakaf yang telah diamanahkan masyarakat sehingga dapat memberikan hasil, surplus dan manfaat nyata dalam meningkatkan kesejahteraan masyarakat; Menjalin sinergi dengan seluruh stakeholder yang terkait dalam meningkatkan peran aktif wakaf dalam meningkatkan kesejahteraan masyarakat.
Event identification risiko dilakukan khusus pada proses kerja manajemen wakaf tanah/bangunan sesuai. Pada masing-masing jenis wakaf tersebut dijabarkan lebih detail proses kerja mulai dari proses manajemen penghimpunan aset wakaf, manajemen pengelolaan dan pengembangan aset wakaf, hingga manajemen penyaluran dan pendayagunaan manfaat wakaf.

\section{Identifikasi, Pengukuran, dan Respon Risiko}

Hasil identifikasi risiko berupa daftar risiko, dampak, dan langkah mitigasinya berdasarkan daftar risiko dapat dilihat pada Tabel 4 untuk kelompok risiko penghimpunan wakaf, Tabel 5 untuk kelompok risiko pengelolaan wakaf, dan Tabel 6 untuk kelompok risiko penyaluran wakaf. 
Tabel 4. Kelompok risiko manajemen penghimpunan wakaf tanah

\begin{tabular}{|c|c|c|c|c|c|}
\hline $\begin{array}{l}\text { No } \\
\text { risiko }\end{array}$ & Daftar risiko & $\begin{array}{l}\text { Nilai } \\
\text { risiko }\end{array}$ & $\begin{array}{c}\text { Tingkat } \\
\text { risiko }\end{array}$ & Dampak & Mitigasi \\
\hline A1 & $\begin{array}{l}\text { Wakif (pemberi } \\
\text { wakaf) tidak tahu } \\
\text { ketentuan wakaf } \\
\text { dan bangunan }\end{array}$ & 6 & Medium & $\begin{array}{l}\text { 1. Proses wakaf terhambat } \\
\text { 2. Wakif tidak tertarik untuk } \\
\text { berwakaf }\end{array}$ & $\begin{array}{l}\text { 1. Pendampingan langsung dari } \\
\text { nazir }\end{array}$ \\
\hline A2 & $\begin{array}{l}\text { Dokumen } \\
\text { kepemilikan } \\
\text { harta wakaf tidak } \\
\text { lengkap }\end{array}$ & 4 & Low & $\begin{array}{l}\text { 1. Proses wakaf terhambat } \\
\text { 2. Wakif gagal berwakaf }\end{array}$ & $\begin{array}{l}\text { 1. Memastikan dokumentasi } \\
\text { lengkap di awal proses wakaf }\end{array}$ \\
\hline A3 & $\begin{array}{l}\text { Ahli waris } \\
\text { (keluarga wakif) } \\
\text { menolak }\end{array}$ & 9 & High & 1. Proses wakaf batal & $\begin{array}{l}\text { 1. Melengkapi surat persetujuan } \\
\text { ahli waris } \\
\text { 2. Membantu mediasi keluarga } \\
\text { wakif }\end{array}$ \\
\hline A4 & $\begin{array}{l}\text { Lokasi harta } \\
\text { wakaf tidak } \\
\text { strategis }\end{array}$ & 9 & High & $\begin{array}{l}\text { 1. Aset wakaf tidak bisa di } \\
\text { produktifkan }\end{array}$ & $\begin{array}{l}\text { 1. Dilakukan ruislag sesuai izin } \\
\text { wakif }\end{array}$ \\
\hline A5 & $\begin{array}{l}\text { Harta wakaf } \\
\text { masih dalam } \\
\text { sengketa }\end{array}$ & 9 & High & 1. Proses wakaf batal & $\begin{array}{l}\text { 1. Mengurus surat bebas sengketa } \\
\text { di kelurahan }\end{array}$ \\
\hline A6 & $\begin{array}{l}\text { Harta wakaf } \\
\text { tidak potensial }\end{array}$ & 6 & Medium & $\begin{array}{l}\text { 1. Produktifitas aset wakaf kurang } \\
\text { maksimal } \\
\text { 2. Manfaat wakaf kecil dan } \\
\text { tidak sebanding dengan biaya } \\
\text { operasional }\end{array}$ & $\begin{array}{l}\text { 1. Dilakukan ruislag sesuai izin } \\
\text { wakif } \\
\text { 2. Merubah cara pengelolaan aset } \\
\text { wakaf }\end{array}$ \\
\hline A7 & $\begin{array}{l}\text { Harta wakaf } \\
\text { adalah harta } \\
\text { haram/berasal } \\
\text { dari transaksi } \\
\text { tidak halal }\end{array}$ & 9 & High & $\begin{array}{l}\text { 1. Pelanggaran syariah QS. Al } \\
\text { Baqarah: } 267 \text { mengenai anjuran } \\
\text { bersedekah dengan harta halal } \\
\text { 2. Aset wakaf tercampur dengan harta } \\
\text { haram. } \\
\text { 3. Terjadi pelanggaran PP No.42 } \\
\text { 4. Reputasi Dompet Dhuafa menurun }\end{array}$ & $\begin{array}{l}\text { 1. Melaksanakan perintah QS. Al } \\
\text { Baqarah: } 267 \\
\text { 2. Melaksanakan PP No } 42 \text { Tahun } \\
\text { 2006 pasal } 22 \text { ayat } 3 \mathrm{~b} \text { "Wakif } \\
\text { wajib menjelaskan status } \\
\text { kepemilikan dan asal usul uang } \\
\text { yang diwakafkan". } \\
\text { 3. Membuat SOP penerimaan dana } \\
\text { sesuai dengan undang-undang. } \\
\text { 4. Membuat disclaimer bahwa } \\
\text { nazir tidak menerima wakaf } \\
\text { uang dari hasil kejahatan dan } \\
\text { larangan lain sesuai ketentuan } \\
\text { syariah }\end{array}$ \\
\hline A8 & $\begin{array}{l}\text { Wakif tidak } \\
\text { paham hukum }\end{array}$ & 4 & Low & $\begin{array}{l}\text { 1. Menghambat proses peralihan hak } \\
\text { hukum }\end{array}$ & $\begin{array}{l}\text { 1. Pendampingan langsung dari } \\
\text { nazir }\end{array}$ \\
\hline A9 & $\begin{array}{l}\text { Dokumen harta } \\
\text { wakaf tidak } \\
\text { lengkap/tidak } \\
\text { memenuhi syarat }\end{array}$ & 9 & High & $\begin{array}{l}\text { 1. Proses wakaf terhambat } \\
\text { 2. Wakif gagal berwakaf }\end{array}$ & $\begin{array}{l}\text { 1. Memastikan dokumentasi } \\
\text { lengkap di awal proses wakaf }\end{array}$ \\
\hline A10 & $\begin{array}{l}\text { Proses peralihan } \\
\text { hak hukum } \\
\text { memerlukan } \\
\text { biaya banyak }\end{array}$ & 9 & High & $\begin{array}{l}\text { 1. Menghambat hingga membatalkan } \\
\text { proses wakaf }\end{array}$ & $\begin{array}{l}\text { 1. Membuat kesepakatan diawal } \\
\text { proses bahwa biaya peralihan } \\
\text { hak hukum ditanggung oleh } \\
\text { wakif }\end{array}$ \\
\hline A11 & $\begin{array}{l}\text { Kurang } \\
\text { lengkapnya } \\
\text { kebijakan } \\
\text { pemerintah yang } \\
\text { mengatur wakaf }\end{array}$ & 9 & High & $\begin{array}{l}\text { 1. Menghambat proses peralihan hak } \\
\text { hukum } \\
\text { 2. Menghambat pengembangan aset } \\
\text { wakaf } \\
\text { 3. Kurang efektifnya pengelolaan } \\
\text { aset wakaf }\end{array}$ & $\begin{array}{l}\text { 1. Konsolidasi dengan pemerintah, } \\
\text { Badan Wakaf Indonesia (BWI) } \\
\text { dan nazir wakaf lain } \\
\text { 2. Memberikan usulan untuk } \\
\text { melengkapi regulasi yang pro } \\
\text { wakaf seperti simplikasi proses } \\
\text { di agraria }\end{array}$ \\
\hline A12 & $\begin{array}{l}\text { Wakif tidak hadir } \\
\text { saat ikrar wakaf } \\
\text { di KUA }\end{array}$ & 2 & Low & $\begin{array}{l}\text { 1. Reschedule ikrar wakaf } \\
\text { 2. Ikrar wakaf batal } \\
\text { 3. Terjadi pelanggaran kepatuhan UU }\end{array}$ & $\begin{array}{l}\text { 1. Memastikan kehadiran wakif } \\
\text { saat ikrar wakaf dilakukan }\end{array}$ \\
\hline A13 & $\begin{array}{l}\text { Proses di agraria } \\
\text { cukup lama } \\
\text { sehingga harta } \\
\text { wakaf idle }\end{array}$ & 12 & High & $\begin{array}{l}\text { 1. Aset idle dan tidak menghasilkan } \\
\text { manfaat wakaf }\end{array}$ & $\begin{array}{l}\text { 1. Menggunakan jasa pihak ke } 3 \\
\text { untuk pengurusan dokumen di } \\
\text { agraria }\end{array}$ \\
\hline
\end{tabular}


Tabel 4. Kelompok risiko manajemen penghimpunan wakaf tanah (lanjutan)

\begin{tabular}{clccll}
\hline $\begin{array}{c}\text { No } \\
\text { risiko }\end{array}$ & Daftar risiko & $\begin{array}{c}\text { Nilai } \\
\text { risiko }\end{array}$ & $\begin{array}{c}\text { Tingkat } \\
\text { risiko }\end{array}$ & Dampak & Mitigasi \\
\hline A14 & $\begin{array}{l}\text { Ikrar wakaf } \\
\text { dilakukan tanpa } \\
\text { dokumentasi }\end{array}$ & 3 & Low & $\begin{array}{l}\text { 1. Pelanggaran syariah QS. Al } \\
\text { Baqoroh: 282-283 mengenai } \\
\text { perintah mencatat mualamah tidak } \\
\text { tunai }\end{array}$ & $\begin{array}{l}\text { 1. Melakukan pencatatan } \\
\text { dokumentasi sesuai QS. Al } \\
\text { Baqarah 282-283 }\end{array}$ \\
2. Menimbulkan sengketa hukum \\
A15
\end{tabular}

Tabel 5. Kelompok risiko manajemen pengelolaa wakaf tanah

\begin{tabular}{|c|c|c|c|c|c|}
\hline $\begin{array}{l}\text { No } \\
\text { risiko }\end{array}$ & Daftar risiko & $\begin{array}{l}\text { Nilai } \\
\text { risiko }\end{array}$ & $\begin{array}{l}\text { Tingkat } \\
\text { risiko }\end{array}$ & Dampak & Mitigasi \\
\hline B16 & $\begin{array}{l}\text { Nazir tidak } \\
\text { memiliki } \\
\text { kompetensi } \\
\text { mengelola harta } \\
\text { wakaf sesuai } \\
\text { harapan wakif }\end{array}$ & 6 & Medium & $\begin{array}{l}\text { 1. Pelanggaran syariah atas HR. } \\
\text { Bukhari No. } 6015 \text { tentang akibat } \\
\text { urusan yang dilakukan bukan oleh } \\
\text { ahlinya } \\
\text { 2. Pengelolaan aset tidak maksimal } \\
\text { 3. Manfaat wakaf yang dihasilkan } \\
\text { tidak maksimal }\end{array}$ & $\begin{array}{l}\text { 1. Meningkatkan kompetensi dan } \\
\text { SDM Nazir secara bertahap } \\
\text { melalui program training } \\
\text { 2. Menggandeng pihak ke } 3 \\
\text { untuk mengelola aset dibawah } \\
\text { pengawasan nazir }\end{array}$ \\
\hline B17 & $\begin{array}{l}\text { Wakif tidak } \\
\text { setuju dengan } \\
\text { bisnis plan yang } \\
\text { dibuat }\end{array}$ & 4 & Low & $\begin{array}{l}\text { 1. Wakif membatalkan wakaf } \\
\text { 2. Tidak tercapainya target fundrising }\end{array}$ & $\begin{array}{l}\text { 1. Membuat bisnis plan yang } \\
\text { disepakati bersama wakif } \\
\text { 2. Membuat program wakaf dulu } \\
\text { baru melakukan fundrising } \\
\text { wakaf }\end{array}$ \\
\hline B18 & $\begin{array}{l}\text { Nazir salah } \\
\text { dalam membuat } \\
\text { bisnis plan }\end{array}$ & 6 & Medium & $\begin{array}{l}\text { 1. Program wakaf tidak berjalan } \\
\text { 2. Surplus wakaf tidak maksimal. }\end{array}$ & 1. Evaluasi bisnis plan \\
\hline E19 & $\begin{array}{l}\text { Bisnis plan } \\
\text { membutuhkan } \\
\text { dana yang besar }\end{array}$ & 12 & High & $\begin{array}{l}\text { 1. Pembangunan aset wakaf } \\
\text { membutuhkan waktu yang lama } \\
\text { 2. Pembangunan aset wakaf macet }\end{array}$ & $\begin{array}{l}\text { 1. Cari pihak ke } 3 \text { yang bisa } \\
\text { membiayai projek kita } \\
\text { 2. Evaluasi bentuk dan media } \\
\text { fundrising wakaf uang }\end{array}$ \\
\hline E20 & $\begin{array}{l}\text { Aset wakaf tidak } \\
\text { produktif }\end{array}$ & 8 & Medium & $\begin{array}{l}\text { 1. Ada pengeluaran biaya } \\
\text { pembayaran PBB }\end{array}$ & $\begin{array}{l}\text { 1. Melakukan Tukar Guling } \\
\text { (Ruislag) }\end{array}$ \\
\hline E21 & $\begin{array}{l}\text { Operasional } \\
\text { nazir } \\
\text { membutuhkan } \\
\text { dana yang } \\
\text { besar, lebih dari } \\
10 \% \text { dana yang } \\
\text { dihasilkan dari } \\
\text { pemproduktifan } \\
\text { dana wakaf }\end{array}$ & 9 & High & $\begin{array}{l}\text { 1. Terhambatnya pengembangan aset } \\
\text { wakaf } \\
\text { 2. Manfaat wakaf yang dihasilkan } \\
\text { tidak sebanding dengan biaya } \\
\text { operasional }\end{array}$ & 1. Menggandeng pihak ketiga \\
\hline E22 & $\begin{array}{l}\text { Keterlambatan } \\
\text { penerbitan } \\
\text { laporan } \\
\text { keuangan dan } \\
\text { kegiatan wakaf }\end{array}$ & 4 & Low & $\begin{array}{l}\text { 1. Berkurangnya kepercayaan wakif } \\
\text { 2. Reputasi DD menurun }\end{array}$ & $\begin{array}{l}\text { 1. Evaluasi mitra kerja di daerah } \\
\text { atas laporan fundrising daerah } \\
\text { 2. Membuat sistem pelaporan } \\
\text { berbasis IT di website sehingga } \\
\text { wakif bisa langsung melaporkan } \\
\text { bukti transfer wakaf sehingga } \\
\text { laporan wakaf bisa langsung } \\
\text { terlapor ke DD pusat }\end{array}$ \\
\hline $\mathrm{B} 23$ & $\begin{array}{l}\text { Adanya } \\
\text { depresiasi harga } \\
\text { bangunan wakaf }\end{array}$ & 9 & High & $\begin{array}{l}\text { 1. Biaya maintenance tinggi } \\
\text { 2. Tidak maksimalnya manfaat wakaf } \\
\text { yang dihasilkan }\end{array}$ & $\begin{array}{l}\text { 1. Menggunakan dana cadangan } \\
30 \% \text { dari surplus wakaf untuk } \\
\text { maintenance }\end{array}$ \\
\hline
\end{tabular}


Tabel 5. Kelompok risiko manajemen pengelolaa wakaf tanah (lanjutan)

\begin{tabular}{|c|c|c|c|c|c|}
\hline $\begin{array}{l}\text { No } \\
\text { risiko }\end{array}$ & Daftar risiko & $\begin{array}{l}\text { Nilai } \\
\text { risiko }\end{array}$ & $\begin{array}{l}\text { Tingkat } \\
\text { risiko }\end{array}$ & Dampak & Mitigasi \\
\hline B24 & $\begin{array}{l}\text { Management nazir } \\
\text { tidak sepakat dengan } \\
\text { program pengelolaan } \\
\text { harta wakaf yang } \\
\text { dipilih }\end{array}$ & 4 & Low & 1. Program tidak terlaksana & $\begin{array}{l}\text { 1. Membuat program baru } \\
\text { yang disetujui manajemen }\end{array}$ \\
\hline B25 & $\begin{array}{l}\text { Harta wakaf rusak, } \\
\text { terbakar, hilang, } \\
\text { tergusur, berkurang } \\
\text { karena rugi. }\end{array}$ & 6 & Medium & $\begin{array}{l}\text { 1. Terjadi pelanggaran syariah HR } \\
\text { Bukhari No. } 2558 \text { mengenai sifat } \\
\text { kekal harta wakaf } \\
\text { 2. Menurunnya kepercayaan wakif } \\
\text { 3. Reputasi Dompet Dhuafa } \\
\text { menurun }\end{array}$ & $\begin{array}{l}\text { 1. Mengasuransikan aset } \\
\text { wakaf } \\
\text { 2. Melakukan ruislah aset } \\
\text { wakaf }\end{array}$ \\
\hline B26 & $\begin{array}{l}\text { Lokasi harta wakaf } \\
\text { jauh sehingga nazir } \\
\text { sulit memonitor dan } \\
\text { mengoperasikannya. }\end{array}$ & 9 & High & $\begin{array}{l}\text { 1. Nazir sulit memonitor dan } \\
\text { mengelola aset wakaf } \\
\text { 2. Keterlambatan pendistribusian } \\
\text { surplus wakaf }\end{array}$ & $\begin{array}{l}\text { 1. Kerjasama dengan mitra } \\
\text { lokal }\end{array}$ \\
\hline B27 & $\begin{array}{l}\text { Adanya moral hazard } \\
\text { oleh Nazir/Oknum } \\
\text { Nazir }\end{array}$ & 5 & Medium & $\begin{array}{l}\text { 1. Terjadi pelanggaran syariah QS } \\
\text { An Nisa: } 58 \text { mengenai kewajiban } \\
\text { menunaikan amanah } \\
\text { 2. Menurunnya kepercayaan wakif } \\
\text { 3. Reputasi Dompet Dhuafa } \\
\text { menurun }\end{array}$ & $\begin{array}{l}\text { 1. Memperbaiki pola screeing } \\
\text { calon anggota nazir } \\
\text { 2. Sosialisasi SOP ke anggota } \\
\text { nazir } \\
\text { 3. Meminimalkan transaksi } \\
\text { cash person to person }\end{array}$ \\
\hline B28 & $\begin{array}{l}\text { Pendayagunaan harta } \\
\text { wakaf tidak sesuai } \\
\text { dengan potensinya }\end{array}$ & 6 & Medium & $\begin{array}{l}\text { 1. Manfaat wakaf yang dihasilkan } \\
\text { tidak maksimal } \\
\text { 2. Berkurangnya kepercayaan wakif } \\
\text { 3. Kompetensi nazir diragukan }\end{array}$ & $\begin{array}{l}\text { 1. Evaluasi program } \\
\text { pengembangan aset wakaf } \\
\text { 2. Menggandeng pihak ketiga }\end{array}$ \\
\hline B29 & $\begin{array}{l}\text { Kurangnya } \\
\text { akuntabilitas dalam } \\
\text { pengelolaan dana } \\
\text { wakaf }\end{array}$ & 6 & Medium & $\begin{array}{l}\text { 1. Menurunnya kepercayaan wakif } \\
\text { 2. Reputasi Dompet Dhuafa } \\
\text { menurun }\end{array}$ & $\begin{array}{l}\text { 1. Memastikan audit internal } \\
\text { dan eksternal berjalan }\end{array}$ \\
\hline $\mathrm{B} 30$ & $\begin{array}{l}\text { Tidak ada pelatihan } \\
\text { SDM nadzir yang } \\
\text { berkesinambungan } \\
\text { dari pemerintah }\end{array}$ & 9 & High & $\begin{array}{l}\text { 1. Tidak meningkatnya kompetensi } \\
\text { nazir } \\
\text { 2. Program pengembangan aset } \\
\text { wakaf tidak maksimal } \\
\text { 3. Hasil manfaat wakaf kurang } \\
\text { maksimal }\end{array}$ & $\begin{array}{l}\text { 1. Membuat program training } \\
\text { untuk meningkatkan } \\
\text { kompetensi dan SDM nazir } \\
\text { 2. Menggandeng BWI dan } \\
\text { Kemenang bidang wakaf }\end{array}$ \\
\hline B31 & $\begin{array}{l}\text { Risiko kurang } \\
\text { produktifnya harta } \\
\text { wakaf karena } \\
\text { pengelolaan wakaf } \\
\text { mengikuti kebiasaan } \\
\text { atau adat istiadat }\end{array}$ & 9 & High & $\begin{array}{l}\text { 1. Program pengembangan aset } \\
\text { wakaf tidak maksimal } \\
\text { 2. Hasil manfaat wakaf kurang } \\
\text { maksimal }\end{array}$ & $\begin{array}{l}\text { 1. Membuat bisnis plan yang } \\
\text { disepakati bersama wakif } \\
\text { 2. Membuat program wakaf } \\
\text { dulu baru melakukan } \\
\text { fundrising wakaf }\end{array}$ \\
\hline B32 & $\begin{array}{l}\text { Pergantian generasi } \\
\text { nazir mungkin } \\
\text { menimbulkan konflik }\end{array}$ & 4 & Low & $\begin{array}{l}\text { 1. Operasional nazir menjadi } \\
\text { kurang efektif }\end{array}$ & $\begin{array}{l}\text { 1. Membuat SOP dan aturan } \\
\text { kerja yang lengkap }\end{array}$ \\
\hline B33 & Risiko force majeure & 9 & High & 1. Menghambat operasional nazir & $\begin{array}{l}\text { 1. Mengasuransikan aset } \\
\text { wakaf }\end{array}$ \\
\hline B34 & $\begin{array}{l}\text { Tanah wakaf } \\
\text { idle karena dana } \\
\text { pengembangan } \\
\text { terbatas }\end{array}$ & 9 & High & $\begin{array}{l}\text { 1. Program pengembangan aset } \\
\text { wakaf tidak maksimal } \\
\text { 2. Hasil manfaat wakaf kurang } \\
\text { maksimal }\end{array}$ & 1. Menggandeng pihak ketiga \\
\hline
\end{tabular}


Tabel 6. Kelompok risiko manajemen penyaluran wakaf tanah

\begin{tabular}{|c|c|c|c|c|c|}
\hline $\begin{array}{l}\text { No } \\
\text { risiko }\end{array}$ & Daftar risiko & $\begin{array}{l}\text { Nilai } \\
\text { risiko }\end{array}$ & $\begin{array}{l}\text { Tingkat } \\
\text { risiko }\end{array}$ & Dampak & Mitigasi \\
\hline $\mathrm{C} 35$ & $\begin{array}{l}\text { Kompetensi } \\
\text { nazir kurang } \\
\text { dalam membuat } \\
\text { perencanaan } \\
\text { penyaluran hasil } \\
\text { harta wakaf yang } \\
\text { efektif }\end{array}$ & 4 & Low & $\begin{array}{l}\text { 1. Kurang efektifnya program } \\
\text { penyaluran }\end{array}$ & $\begin{array}{l}\text { 1. Peningkatan SDM nazir } \\
\text { dan kreatifitas nazir dalam } \\
\text { pembuatan program } \\
\text { penyaluran }\end{array}$ \\
\hline $\mathrm{C} 36$ & $\begin{array}{l}\text { Program } \\
\text { penyaluran manfaat } \\
\text { harta wakaf tidak } \\
\text { efektif }\end{array}$ & 6 & Medium & $\begin{array}{l}\text { 1. Kurang maksimalnya manfaat yg } \\
\text { dirasakan oleh mauquf 'alaih }\end{array}$ & 1. Evaluasi program penyaluran \\
\hline $\mathrm{C} 37$ & $\begin{array}{l}\text { Nazir tidak } \\
\text { menyalurkan hasil } \\
\text { harta wakaf ke } \\
\text { mauquf 'alaih yang } \\
\text { direkomendasikan } \\
\text { wakif }\end{array}$ & 4 & Low & $\begin{array}{l}\text { 1. Terjadi pelanggaran syariah QS } \\
\text { An Nisa: } 58 \text { mengenai kewajiban } \\
\text { menunaikan amanah } \\
\text { 2. Menurunnya kepercayaan wakif } \\
\text { 3. Reputasi Dompet Dhuafa } \\
\text { menurun }\end{array}$ & $\begin{array}{l}\text { 1. Menyalurkan sesuai } \\
\text { rekomendasi wakif }\end{array}$ \\
\hline $\mathrm{C} 38$ & $\begin{array}{l}\text { Adanya pemalsuan } \\
\text { data mauquf 'alaih }\end{array}$ & 6 & Medium & $\begin{array}{l}\text { 1. Salah sasaran mauquf 'alaih } \\
\text { 2. Penyaluran surplus wakaf tidak } \\
\text { efektif } \\
\text { 3. Reputasi Dompet Dhuafa } \\
\text { menurun }\end{array}$ & $\begin{array}{l}\text { 1. Melakukan survey atas } \\
\text { mauquf 'alaih } \\
\text { 2. Melakukan audit rutin atas } \\
\text { database mauquf 'alaih }\end{array}$ \\
\hline C39 & $\begin{array}{l}\text { Surplus wakaf } \\
\text { yang diterima tidak } \\
\text { disalurkan dengan } \\
\text { benar (terlambat, } \\
\text { tidak sesuai, salah } \\
\text { sasaran, proses } \\
\text { lama, proses sulit, } \\
\text { mubazir) }\end{array}$ & 6 & Medium & $\begin{array}{l}\text { 1. Menurunkan kepercayaan wakif } \\
\text { 2. Menurunkan reputasi Dompet } \\
\text { Dhuafa } \\
\text { 3. Mauquf 'alaih tidak bisa } \\
\text { memenuhi kebutuhan dasar } \\
\text { pendidikan dan kesehatan } \\
\text { 4. Potensi terjadi fraud } \\
\text { 5. Kurang maksimalnya manfaat } \\
\text { wakaf }\end{array}$ & $\begin{array}{l}\text { 1. Evaluasi SOP penyaluran } \\
\text { 2. Evaluasi program penyaluran } \\
\text { dan bisnis proses yang efektif } \\
\text { dan efisien } \\
\text { 3. Tindakan pencegahan dan } \\
\text { perbaikan sistem }\end{array}$ \\
\hline $\mathrm{C} 40$ & $\begin{array}{l}\text { Nadzir dan Mauquf } \\
\text { 'alaih melakukan } \\
\text { manipulasi data }\end{array}$ & 6 & Medium & $\begin{array}{l}\text { 1. Menurunkan kepercayaan wakif } \\
\text { 2. Menurunkan reputasi Dompet } \\
\text { Dhuafa } \\
\text { 3. Potensi terjadi fraud }\end{array}$ & $\begin{array}{l}\text { 1. Evaluasi SOP penyaluran } \\
\text { 2. Evaluasi program penyaluran } \\
\text { dan bisnis proses yang efektif } \\
\text { dan efisien } \\
\text { 3. Tindakan pencegahan dan } \\
\text { perbaikan sistem }\end{array}$ \\
\hline $\mathrm{C} 41$ & $\begin{array}{l}\text { Manfaat wakaf } \\
\text { kesehatan tidak } \\
\text { diketahui mauquf } \\
\text { 'alaih }\end{array}$ & 4 & Low & $\begin{array}{l}\text { 1. Kurang maksimalnya manfaat yg } \\
\text { dirasakan oleh mauquf 'alaih }\end{array}$ & $\begin{array}{l}\text { 1. Memperbaiki program } \\
\text { sosialisasi program ke } \\
\text { mauquf 'alaih }\end{array}$ \\
\hline $\mathrm{C} 42$ & $\begin{array}{l}\text { Lokasi fasilitas } \\
\text { kesehatan jauh } \\
\text { dari lokasi mauquf } \\
\text { 'alaih }\end{array}$ & 9 & High & $\begin{array}{l}\text { 1. Mauquf alaih tidak terlayani } \\
\text { semua } \\
\text { 2. Mauquf 'alaih tidak mampu } \\
\text { membayar biaya transportasi } \\
\text { menuju fasilitas kesehatan }\end{array}$ & $\begin{array}{l}\text { 1. Menggandeng mitra lokal } \\
\text { 2. Membuat program jemput } \\
\text { bola dengan mendatangi } \\
\text { mauquf 'alaih secara reguler }\end{array}$ \\
\hline $\mathrm{C} 43$ & $\begin{array}{l}\text { Nazir tidak } \\
\text { memiliki } \\
\text { kompetensi } \\
\text { manajemen rumah } \\
\text { sakit }\end{array}$ & 9 & High & $\begin{array}{l}\text { 1. Kurang maksimalnya manfaat yg } \\
\text { dirasakan oleh mauquf 'alaih } \\
\text { 2. Menurunnya kepercayaan wakif }\end{array}$ & $\begin{array}{l}\text { 1. Meningkatkan kompetensi } \\
\text { nazir dengan menyusun } \\
\text { program training nazir } \\
\text { 2. Menggandeng pihak ketiga }\end{array}$ \\
\hline $\mathrm{C} 44$ & $\begin{array}{l}\text { Jumlah mauquf } \\
\text { 'alaih lebih besar } \\
\text { dari kemampuan } \\
\text { nazir/kapasitas } \\
\text { fasilitas wakaf }\end{array}$ & 9 & High & $\begin{array}{l}\text { 1. Mauquf alaih tidak terlayani } \\
\text { semua } \\
\text { 2. Menurunnya kepercayaan mauquf } \\
\text { 'alaih }\end{array}$ & $\begin{array}{l}\text { 1. Meningkatkan kapasitas } \\
\text { manfaat wakaf dengan dana } \\
\text { lain berupa zakat dan infak } \\
\text { 2. Menggandeng pihak ketiga }\end{array}$ \\
\hline
\end{tabular}


Tabel 6. Kelompok risiko manajemen penyaluran wakaf tanah (lanjutan)

\begin{tabular}{|c|c|c|c|c|c|}
\hline $\begin{array}{l}\text { No } \\
\text { risiko }\end{array}$ & Daftar risiko & $\begin{array}{l}\text { Nilai } \\
\text { risiko }\end{array}$ & $\begin{array}{l}\text { Tingkat } \\
\text { risiko }\end{array}$ & Dampak & Mitigasi \\
\hline $\mathrm{C} 45$ & $\begin{array}{l}\text { Nazir lebih banyak } \\
\text { mengalokasikan } \\
\text { surplus wakaf } \\
\text { untuk reinvestasi } \\
\text { daripada disalurkan } \\
\text { ke mauquf 'alaih }\end{array}$ & 4 & Low & $\begin{array}{l}\text { 1. Menurunnya kepercayaan wakif } \\
\text { 2. Reputasi Dompet Dhuafa } \\
\text { menurun }\end{array}$ & $\begin{array}{l}\text { 1. Membuat aturan pembagian } \\
\text { porsi manfaat wakaf } \\
\text { (60\% mauquf 'alaih, } 30 \% \\
\text { Re-investasi dan biaya } \\
\text { operasional) }\end{array}$ \\
\hline $\mathrm{C} 46$ & $\begin{array}{l}\text { Keuntungan } \\
\text { pengelolaan wakaf } \\
\text { tidak sebanding } \\
\text { dengan aktual biaya } \\
\text { re-investasi yang } \\
\text { dibutuhkan }\end{array}$ & 9 & High & $\begin{array}{l}\text { 1. Pengembangan aset wakaf } \\
\text { terhambat } \\
\text { 2. Project re-investasi macet }\end{array}$ & $\begin{array}{l}\text { 1. Evaluasi program } \\
\text { pengembangan aset wakaf } \\
\text { 2. Menggandeng pihak ketiga }\end{array}$ \\
\hline $\mathrm{C} 47$ & $\begin{array}{l}\text { Project re-investasi } \\
\text { macet }\end{array}$ & 6 & Medium & $\begin{array}{l}\text { 1. Target surplus wakaf tidak } \\
\text { tercapai }\end{array}$ & $\begin{array}{l}\text { 1. Merubah bentuk program } \\
\text { wakaf }\end{array}$ \\
\hline
\end{tabular}

Pada risiko dengan kategori tinggi seperti risiko kurang lengkapnya kebijakan pemerintah juga dialami di Jordania seperti disebutkan dalam penelitian Altheebeh (2016) menyebutkan bahwa kondisi perwakafan di Jordania juga perlu perhatian serius dari pemerintah seperti membuat peraturan yang mendukung program wakaf, mensertifikasi wakaf individu, dan membuat target pengumpulan dana dalam periode tertentu dengan menggunakan metode yang lebih inovatif. Kemudian risiko tinggi lainnya yaitu tidak terdokumentasinya proses wakaf, biaya peralihan status hukum tanah wakaf sesuai dengan hasil penelitian Rashid (2012) menemukan ada enam permasalahan wakaf yaitu urgensi sertifikasi tanah wakaf, meningkatkan partisipasi masyarakat pada wakaf, status wakaf keluarga, mencari alternatif atas tingginya biaya untuk proses hukum tanah wakaf, dan segera menemukan cara pengembangan wakaf properti yg efektif.

Risiko kurang profesionalnya nazir dan risiko idlenya tanah wakaf karena menunggu proses peralihan hukum yang lama juga ditemukan pada penelitian Chowdury et al. (2011) yang menyebutkan kendala manajemen wakaf di Malaysia pemerintah seharusnya menempatkan pegawai bagian perwakafan orang-orang yang qualified dan profesional. Masalah lain masih ada aset wakaf yang dikelola oleh non muslim yang bahkan tidak meyakini ajaran islam. Selain itu, masih banyak tanah wakaf yang idle karena menunggu pengalihan proses hukum dari wakif ke nazir.

Risiko terlambatnya penerbitan laporan keuangan dan kegiatan wakaf juga ditemukan dalan hasil penelitian Sabit dan Hamid (2012) sehingga direkomendasikan melakukan mitigasi risiko wakaf dengan tranparansi laporan keuangan lembaga wakaf dengan dilakukan audit setiap tahun oleh auditor independent.

Risiko kurangnya SDM nazir juga sesuai dengan hasil penelitian Haura et al. (2015) dalam penelitiannya mengenai wakaf uang menyatakan bahwa faktor strategis dalam pengelolaan wakaf uang dipengaruhi faktor internal dan eksternal, yaitu akuntabilitas, produk, dan SDM nazir pada faktor internal dan regulasi, masyarakat, serta demografi pada faktor eksternal. Juga sesuai dengan hasil penelitian Haneef, et al. (2015) dalam penelitiannya mengenai Integration of waqf-Islamic microfinance model for poverty reduction merekomendasikan agar distribusi manfaat wakaf efektif maka harus memberikan pendidikan dan training penerima wakaf agar manfaat wakaf bisa menjadi modal yang produktif.

\section{Pemetaan Risiko}

Setelah melakukan pengukuran tingkat risiko pada manajemen wakaf di Dompet Dhuafa kemudian tingkat risiko dipetakan dengan mengelompokkan dalam empat kategori, yaitu kotak polos untuk kelompok neglible kategori risiko tingkat rendah dengan nilai risiko 1-4 sebanyak 11 risiko, kotak garis arsir horizontal untuk kelompok acceptable kategori risiko tingkat sedang dengan nilai risiko 5-8 sebanyak 15 risiko, kotak arsir polkadot untuk kelompok undesirable kategori risiko tingkat tinggi dengan nilai risiko 9-15 sebanyak 21 risiko, dan kotak arsir x untuk kelompok unacceptable kategori risiko tingkat sangat tinggi dengan nilai risiko 16-20 sebanyak nol risiko sesuai Gambar 3. 


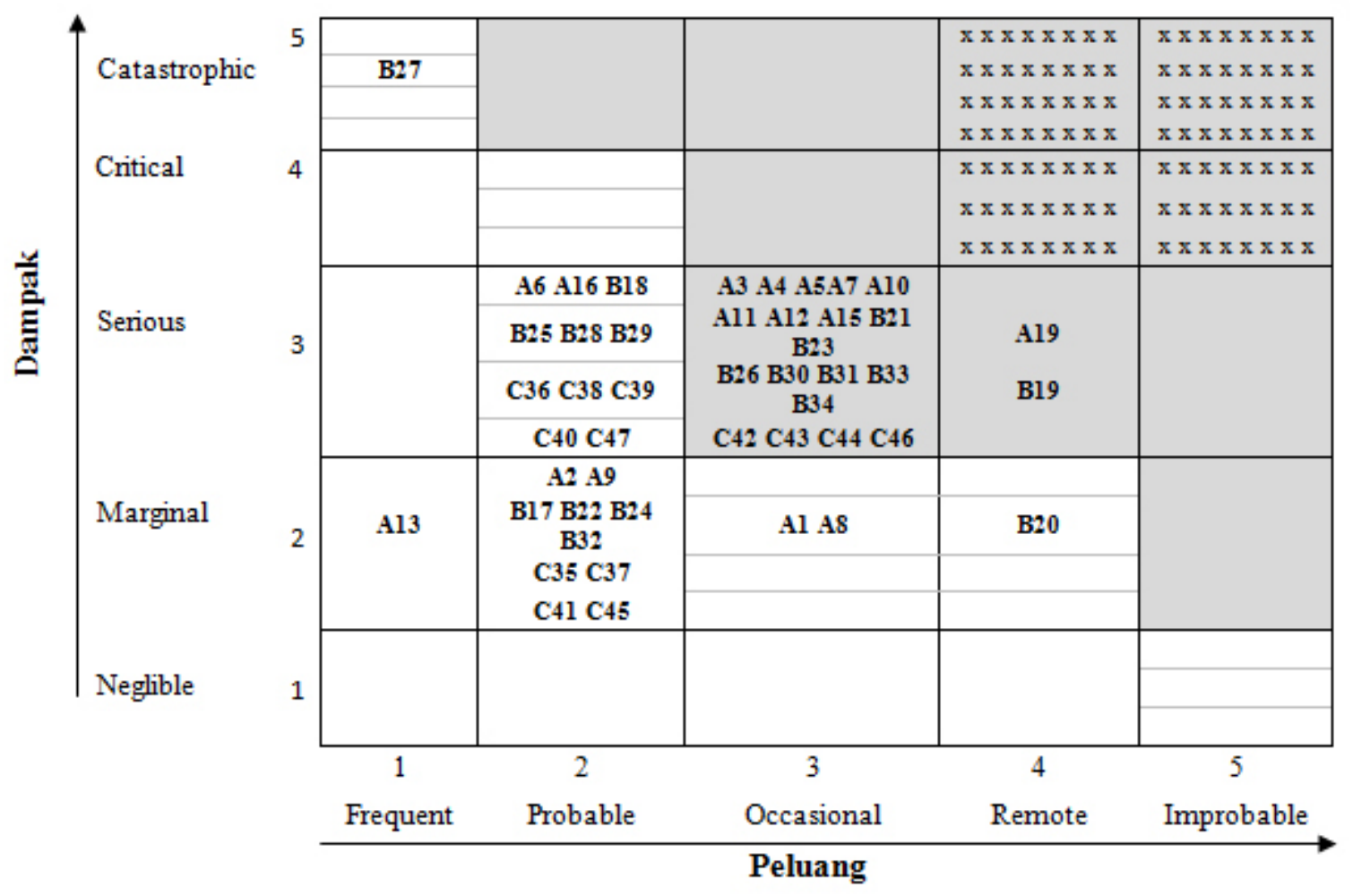

Gambar 3. Peta risiko wakaf tanah Dompet Dhuafa ( $\square$ Tingkat risiko low; $\square$ Tingkat risiko medium; Tingkat risiko high; $\mathrm{XXXXX}$ Tingkat risiko extreme)

Pemetaan ini akan memudahkan manajemen Dompet Dhuafa untuk melihat sebaran ukuran dan dampak risiko pada proses manajemen wakaf tanah. Seperti terlihat pada Gambar 3, terlihat masih banyak risiko tinggi dengan nilai peluang risiko 3 dan nilai dampak 3 sehingga manajemen Dompet Dhuafa perlu memprioritasnya kelompok risiko ini untuk segera ditangani.

\section{Implikasi Manajerial}

Untuk manajemen Dompet Dhuafa, strategi yang dapat dilakukan untuk menerapkan manajemen risiko pada manajemen wakaf mulai dari proses himpunan, pengelolaan, hingga penyaluran seperti membuat divisi khusus manajemen risiko sesuai dengan aturan tata kelola perusahaan atau Good Corporate Governance (GCG), melakukan pemetaan risiko yang lebih detail atas setiap proses dan project manajemen wakaf dan atisipasi yang harus disiapkan, memastikan setiap proses dan project manajemen wakaf melakukan manajemen risiko sampai dengan implementasi strategi respon risiko, dan meningkatkan pemahaman dan kemampuan penerapan manajemen risiko pada setiap level organisasi terutama pada personal kunci pada manajemen wakaf seperti manajer fundrising, manajer pengelolaan aset wakaf, dan manajer penyaluran wakaf memalui pelatihan manajemen risiko, atau buku petunjuk implementasi manajemen risiko yang salah satu sumbernya bisa berasal dari hasil penelitian ini.

Untuk regulator wakaf baik Kementrian Agama bidang wakaf mapun Badan Wakaf Indonesia, hasil penelitian ini diharapkan bisa menjadi acuan untuk melakukan beberapa improvement dalam bidang wakaf dan untuk memininalisir risiko pada manajemen wakaf, strategi yang dapatdilakukansepertimewajibkankepada seluruh nazir wakaf untuk menerapkan manajemen risiko baik dalam proses kerja organisasi maupun pada setiap proyek pengembangan aset wakaf, segera melengkapi beberapa aturan yang mendukung regulasi perwakafan terutama pada kemudahan proses sertifikasi aset wakaf agar 33\% tanah wakaf yang belum tersertifikasi bisa segera tersertifikasi. Selain itu juga sangat diperlukan tambahan aturan untuk kemudahan proses IMB dalam rangka memproduktifkan aset wakaf. Hingga saat ini proses pembuatan IMB aset wakaf masih mengikuti prosedur reguler yang memakan effort besar baik dari segi waktu maupun biaya, membangun sinergi dan kerjasama dengan kementrian agama bidang wakaf, bank syariah nasional maupun internasional, lembaga wakaf lain, MUI dan BWI. Dengan kerja sama ini 
diharapkan dampak sosialisasi akan lebih masif dan lebih efektif.Membuat project wakaf produktif bersama terutama pada program yang membutuhkan dana besar dan bermanfaat lebih luas.

Bagi masyarakat, hasil penelitian ini diharapkan dapat meningkatkan kepercayaan pada lembagalembaga wakaf dengan aktif menjadi donatur, juga aktif melakukan monitor atas kinerja nazir, dan ikut berperan aktif dalam mensosialisasikan program dan kelebihan wakaf.

\section{KESIMPULAN DAN SARAN}

\section{Kesimpulan}

Dalam manajemen risiko wakaf Dompet Dhuafa diidentifikasi total ada 47 risiko pada manajemen wakaf tanah dan bangunan. Risiko tersebut terdiri dari 16 risiko pada proses penghimpunan wakaf, 17 risiko pada proses pengelolaan wakaf dan 13 risiko pada proses penyaluran manfaat wakaf.

Dari total risiko tersebut diukur tingkat risikonya dan dibagi dalam empat kelompok yaitu, risiko ekstrim dengan tingkat penerimaan unacceptable 0 risiko, risiko tingkat tinggi dengan tingkat penerimaan undesirable sebanyak 21, risiko sedang dengan tingkat penerimaan acceptable sebanyak 15 risiko, terakhir risiko rendah dengan tingkat penerimaan neglible sebanyak 11 risiko. Besar tingkat risiko Dompet Dhuafa terlihat pada peta risiko. Risiko utama pada proses penghimpunan terkait dengan proses peralihan hak hukum aset wakaf dari wakif kepada nazir di agraria yang cukup lama sehingga dampaknya adalah aset wakaf idle dan tidak bisa di produktifkan.Sedangkan risiko utama pada proses penyaluran surplus wakaf adalah jumlah mauquf 'alaih yang lebih besar daripada hasil surplus wakaf yang bisa disalurkan. Dampaknya masih banyak mauquf 'alaih yang belum mendapatkan manfaat wakaf dan manfaat yang diberikan masih terbatas seperti pada layanan kesehatan rumah sakit dhuafa tidak bisa memberikan pengganti ongkos pada pasien yang datang berobat dan masih sebatas pengobatan gratis saja.

Strategi mitigasi risiko mengacu pada level respon risiko atas masing-masing tingkat penerimaan risiko. Untuk penerimaan risiko unacceptable maka respon risikonya adalah dengan avoid atau menghindari risiko, risiko undesirable direspon dengan membagi atau mentransfer risiko, risiko acceptable direspon dengan mengurangi risiko, dan risiko neglible direspon dengan menerima risiko. Contoh mitigasi risiko pada proses pengelolaan wakaf dimana proyek pengembangan aset wakaf yang membutuhkan dana sangat besar sehingga berdampak pada proses pembangunan aset wakaf butuh waktu lama bahkan hingga berpotensi macet karena kekurangan dana. Mitigasi yang dilakukan untuk risiko ini adalah dengan mentransfer risiko dengan menggandeng pihak ketiga, yaitu program pembiayaan yang dapat mengcover semua kebutuhan dana pembangunan dan nazir akan mengembalikannya dengan cara mencicil dengan sebagian surplus wakaf yang dihasilkan.

\section{Saran}

Atas hasil penelitian ini berikut beberapa hal yang disarankan mengacu pada risiko-risiko yang ditemukan untuk antisipasi kedepannya seperti membangun sistem database berbasis IT untuk semua proses manajemen wakaf mulai dari database wakif, mauquf 'alaih, penghimpunan, pengelolaan, penyaluran hingga pelaporan. Sehingga dapat mengurangi risiko moral hazard (baik nazir maupun mauquf 'alaih), risiko salah profiling wakif maupun mauquf 'alaih, salah penyaluran manfaat wakaf, keterlambatan penyaluran hingga mengurangi risiko keterlambatan pemberian laporan wakaf ke wakif dan masyarakat. Meningkatkan SDM nazir sehingga dapat mengurangi potensi risiko seperti membuat bisnis plan, membuat strategi promosi, membuat strategi fundrising yang efektif, membuat stategi pengelolaan aset, membuat startegi penyaluran aset, hingga mengetahui proses manajemen rumah sakit untuk mengelola manfaaat wakaf kesehatan. Penelitian selanjutnya bisa melihat lebih dalam hingga financial loss yang dihitung dengan data statistik pada setiap proses mulai dari himpunan, pengelolaan hingga ke proses penyaluran.

\section{DAFTAR PUSTAKA}

Altheebeh ZAH. 2016. Control and development of waqf fund in modern state. International Journal of Managerial Studies and Research 4(2): 4959.

Arifin Z. 2015. Pertumbuhan aset wakaf dan dilema produktifitas. Jurnal Bimas Islam 8(4):659-684.

Arnold V, Benford TS, Hampton C. Sutton SG. 2012. Enterprise risk management as a 
strategic governance mechanism in b2benabled transnational supply chains. Journal of Information System 26(1):51-76.

Chowdhury SR, Chowdhury IA, Muhammad MZ, Yasoa MR. 2012. Problems of waqf administration and proposals for improvement: a study in Malaysia. Journal of Internet Banking and Commerce 17(1): 1-8.

[COSO] Committee of Sponsoring Oranizations of the TreadawayCommission. 2004. Executive Summary of Enterprise Risk Management: Integrated Framework. New Jersey: AICPA/ COSO.

Flanagan R, Norman G. 1993. Risk Management and Construction. New Jersey: Wiley-Blackwell

Godfrey PS. 1996. Control of Risk A Guide to the systematic Management of Riskfrom Contruction. London: CIRIA.

Gondo W. Wibawa BM. 2015. Analisis peta risiko pengeboran di wilayah asset 5 di pertamina EP. Jurnal Manajemen Keuangan 17(2): 113-125.

Haura A, Baga LM, Tanjung H. 2015. Analisis pengelolaan wakaf uang pada koperasi jasa keuangan syariah (pendekatan analytical network process). Jurnal Almuzara'ah 3(2): 89-105.

Masama BT, Ndlovu E, Mambwe T, Rabohome C, Chakabva O, Fologang B, Badze T, Bruwer JP. 2012. Enterprise risk management: a managing 'partner' for business success. African Journal of Business Management 6(48): 11782-11786.

Pradana YA, Rikumahu B. 2014. Penerapan manajemen risiko terhadap perwujudan good governance pada perusahaan asuransi. Jurnal Trikonomika13(2): 195-194.

Rashid SK. 2012. Measures For The Better Management of Awqaf. IIUM Law Journal 20(1): 103-137.

Rozalinda. 2012. Manajemen risiko investasi wakaf uang. Jurnal Islamica 6(2): 300-315.

Sabit MT, Hamid A. 2012. Obstacles of the current concept of waqf to the development of waqf properties and the recommended alternative. Malaysian Journal of Real Estate 1(1): 27-38.

Triyani. N. 2015. Manajemen risiko pada badan amil zakat nasional (BAZNAZ). [Tesis]. Bogor: Institut Pertanian Bogor.

Tsabita K. 2014. Analisis risiko pembiayaan syariah pada sektor pertanian. Jurnal Muzara'ah 2(2): $88-117$.

Ubaid A. 2014. Analisis Hasil dan Metode Fundraising Wakaf Uang Badan Wakaf Indonesia (BWI). Jurnal Bimas Islam 7(4): 605-632.

Wasisto, A. W. 2013. Manajemen risiko pada unit bisnis yayasan (studi kasus: di samboja lodge) [tesis]. Bogor: Institut Pertanian Bogor.

Widiatmanti H. 2015. Penghasilan kelas menengah naik $=$ potensi pajak?. http://www.bppk.kemenkeu. go.id/publikasi/artikel/167-artikel-pajak/21014penghasilan-kelas-menengah-naik-potensipajak [20 Januari 2016].

Wiryani H, Achsani NA, Baga LM. 2013. Pemetaan risiko di industri penyamakan kulit dengan pendekatan ERM. Jurnal Management dan Agribisnis 10(1): 50-59. 